\title{
Asymmetric Diabetic Retinopathy and Carotid Insufficiency: A Correlative Study
}

\author{
MAY I. EL-RASHEDY, M.Sc.*; MALAK I. EL-SHAZLY, M.D.*; FOAD A. ABD ALLAH, M.D.** and \\ ABD EL-AZIZ A. SAAD, M.D.*
}

The Departments of Ophthalmology* and Neurology**, Faculty of Medicine, Cairo University

\begin{abstract}
Background: Diabetic retinopathy occurs in both type 1 and type 2 diabetes mellitus and has been shown that nearly all type 1 and $75 \%$ of type 2 will develop diabetic retinopathy after 15 years duration of diabetes as shown in epidemiological studies. In western population, diabetic retinopathy has been shown to be the cause of visual impairment in $86 \%$ of type 1 diabetic patients and in $33 \%$ of type 2 diabetic patients [1]

Aim of Study: To detect a relationship between carotid system insufficiency and the presence of asymmetric diabetic retinopathy in diabetic patients.

Patients and Methods: A descriptive cross sectional noncontrolled non-randomized study was carried between August 2011 and March 2012 on 20 patients with asymmetric diabetic retinopathy graded and documented with fundus fluorescein angiography (FFA). Assessing the carotid system patency and flow parameters using duplex Ultrasound was then done. Primary outcome was to find a correlation between the diabetic retinopathy asymmetry and carotid system insufficiency in terms of presence of atheromtous plaque, increased intima media thickness (IMT) or decreased flow parameters.
\end{abstract}

Results: $50 \%$ of cases had a degree of carotid insufficiency. The degree of carotid insufficiency in either common carotid artery and/or internal carotid artery ranged from $15 \%$ to $50 \%$ stenosis. And $10 \%$ had increased IMT and $15 \%$ had increased $\mathrm{RI}$ all on the ipsilateral side of the eye with more advanced diabetic retinopathy. And an overall $45 \%$ increase in IMT.

Conclusion: Asymmetric diabetic retinopathy is considered to be the exception rather than the rule as DR is usually symmetric. We found that Carotid stenosis is a contributing factor in causing such asymmetry. So presence of asymmetric DR urges early investigation for detecting carotid system insufficiency and carotid plaques to avoid future strokes.

Key Words: Asymmetric diabetic retinopathy - Carotid stenosis - Carotid plaque.

Correspondence to: Dr. May I. El-Rashedy, The Department of Ophthalmology, Faculty of Medicine, Cairo University

\section{Introduction}

THE retinal changes in patients with diabetes result from five fundamental pathological processes: (i) Formation of retinal capillary microaneurysms, (ii) Development of excessive vascular permeability, (iii) vascular occlusion, (iv) Proliferation of new blood vessels and accompanying fibrous tissue on the surface of the retina and optic disk, and (v) Contraction of these fibrovascular proliferations and the vitreous [2].

Major biochemical pathways have been hypothesized to explain the mechanism of diabetic eye diseases starting initially from hyperglycaemia inducing vascular injury. They include (i) Enhanced glucose flux through the glycol pathway, (ii) Increased intracellular formation of advanced glycation end-products (AGE), (iii) Activation of protein kinase C (PKC) isoforms and (iv) Stimulation of the hexosamine pathway, these mechanisms reflect a hyperglycaemia induced process initiated by superoxide overproduction in the mitochondrial electron transport chain [3].

Diabetic retinopathy usually develops in a symmetric pattern, asymmetric diabetic retinopathy is considered to be the exception rather than the rule. So the cause beyond this asymmetry should be revealed. Various risk factors that can cause asymmetry, by accelerating the diabetic retinopathy changes and increasing its severity, as unilateral PVD or cataract surgery and others by decreasing its progression rate and severity as unilateral Glaucoma or Myopia.

In ocular ischemia syndrome caused by carotid stenosis, diabetic retinopathy is worse up to neovascularization of retina and iris. These patients PRP is of little benefit and visual outcome is usually 
poor unless carotid ischemia is concurrently treated to improve such visual outcome.

The presentation of asymmetric diabetic retinopathy should raise the suspicion for urgent investigation of blood supply to head and neck, by checking the patency of carotid system. Early reversal of carotid stenosis either by stenting or endarterctomy will be the most important way to maintain and/or improve vision in such cases and guard against high morbidity and mortality from cerebrovascular accidents.

\section{Material and Methods}

The study was carried out on 20 patients recruited between August 2011 and March 2012 from ophthalmology outpatient clinic at Cairo University Hospitals, Al-Kasr Al-Aini. Patients with type 1 or 2 diabetes mellitus and asymmetric diabetic retinopathy were included. Patients with other ocular problems that may be a contributing factor for asymmetry as: Unilateral glaucoma, high myopia, optic atrophy and cataract surgery were excluded.

History: Was taken from each patient for, age, sex, type \& duration, of diabetes, Hypertension, Smoking, Stroke.

Complete ophthalmological examination: Including assessing BCVA, Slit lamp examination, IOP measurement an indirect ophthalmoscopy using +20 D lens to assess the optic disc, macula, vessels, four retinal quadrants and periphery for diabetic changes and clinical grading and exclude confounding factors.

Fundus fluorescein angiography: To help documenting and proper grading of diabetic retinopathy and the treatment plan. It was done at Al-Kasr AlAini Laser and Investigative Ophthalmic Unit, using Topcon TRC-50IA machine. Photos were acquiesced using digital camera Sony Power HAD connected to special PC and processed with software Image Net for Windows-C Multi-Format Database for processing the photos for contrast, brightness, saving and printing.

Grading of diabetic retinopathy: The Modified Airlie House Criteria was used for classification and grading of diabetic changes. Asymmetry was defined as more than two stages differences in the grading of retinal diabetic changes between both eyes [4].

Color coded extracranial duplex ultrasonography: Duplex studies were done at Al-Kasr Al-Aini Neurology Department, Neurovascular Ultrasono- graphic Unit, using Phillips HDI 5000 ultrasound equipment. Extracranial vessels (common carotid and internal carotid) were evaluated by real-time imaging using a liner $10 \mathrm{MHz}$ transducer for sagittal, coronal and axial views.

B-mode transverse scanning of vessels to examine the arterial wall morphology, detect intimamedial changes and presence of atheromatous plaques which was defined as a thickness $>2 \mathrm{~mm}$ as measured from the media-adventitia interface to the intima-lumen interface. Longitudinal scanning for quantification of the intima media thickness (IMT) in both CCA as an index for atherosclerotic changes in carotid system, IMT value of $0.1 \mathrm{~cm}$ was chosen as the cut-off measure for IMT, as suggested in literature. Pulsed Duplex for the Internal Carotid artery was done to detect arterial wall stiffness and atherosclerotic changes, by analyzing the flow parameters in terms of peak systolic velocity (PSV) and resistivity index (RI) (normal up to 0.7$)$ [5]

\section{Statistical methods:}

Data were analyzed using Windows statistical software. Descriptive statistics were calculated and numerical data were summarized as mean \pm SD while categorical data were summarized in percentages. Wilcoxon Signed-Rank Test was used to compare numerical to calculate $p$-value between carotid duplex parameters of same side with more advanced DR and less advanced side in which it was considered to be significant if $<0.05$. Correlation between ordinal variables was done using Chisquare and correlation.

\section{Results}

Among the 20 examined patients 9 were males (45\%) and 11 were females (55\%), The mean age was 53.65 years, $\mathrm{SD} \pm 9.27$. All patients had T2DM with a mean duration of 12 years $\mathrm{SD} \pm 7.6 .25 \%$ were smokers and $75 \%$ were hypertensive. Only one patient (case no 15) had a history of previous cerebrovascular stroke.

Ophthalmic examination showed that BCVA ranged from 1.60 to $0.60 \mathrm{LogMAR}$ in the eye with more advanced diabetic retinopathy, and from 1.00 to 0.20 LogMAR in the eye with less advanced diabetic retinopathy, IOP was in normal range (10$18 \mathrm{mmHg}$ ), with a mean $14.05 \mathrm{mmHg}$ in all patients, except for one patient, case who had neovascular glaucoma with IOP $27 \mathrm{mmHg}$.

Grading of diabetic retinopathy severity to detect the asymmetry was done using fundus fluorescein angiography are shown in the table below. 
Table (1): Cases involved in the study.

\begin{tabular}{llllll}
\hline Case & $\begin{array}{l}\text { Age/ } \\
\text { Sex }\end{array}$ & $\begin{array}{l}\text { Yrs of } \\
\text { DM }\end{array}$ & TTT & \multicolumn{1}{c}{ OD } & \multicolumn{1}{c}{ OS } \\
\hline 1 & $60 / \mathrm{M}$ & 30 & Insulin & Mild PDR & Mild NPDR \\
2 & $54 / \mathrm{M}$ & 20 & Insulin & Mild PDR & Mild NPDR \\
3 & $48 / \mathrm{F}$ & 6 & Insulin & Mild PDR & Mild NPDR \\
4 & $47 / \mathrm{M}$ & 6 & OHD & High risk PDR & Moderate NPDR \\
5 & $51 / \mathrm{F}$ & 8 & Insulin & Moderate NPDR & Normal \\
6 & $36 / \mathrm{M}$ & 1 & Insulin & Severe NPDR & High risk PDR \\
7 & $50 / \mathrm{F}$ & 14 & OHD & Mild NPDR & Severe NPDR \\
8 & $43 / \mathrm{M}$ & 20 & Insulin & Advanced PDR & Mild PDR \\
9 & $58 / \mathrm{F}$ & 17 & Insulin & Mild NPDR & Advanced PDR \\
10 & $61 / \mathrm{M}$ & 12 & Insulin & Severe NPDR & Mild NPDR \\
11 & $66 / \mathrm{F}$ & 20 & Insulin & High risk PDR & Moderate NPDR \\
12 & $58 / \mathrm{F}$ & 5 & Insulin & Advanced PDR & Mild PDR \\
13 & $68 / \mathrm{M}$ & 10 & Insulin & Mild NPDR & Advanced PDR \\
14 & $57 / \mathrm{F}$ & 15 & Insulin & Advanced PDR & Mild PDR \\
15 & $70 / \mathrm{M}$ & 25 & Insulin & Advanced PDR & Mild PDR \\
16 & $45 / \mathrm{F}$ & 10 & Insulin & Advanced PDR & Mild NPDR \\
17 & $48 / \mathrm{F}$ & 3 & OHD & Advanced PDR & Mild PDR \\
18 & $45 / \mathrm{F}$ & 7 & OHD & Mild NPDR & Mild PDR \\
19 & $63 / \mathrm{M}$ & 10 & OHD & Mild NPDR & Advanced PDR \\
20 & $45 / \mathrm{F}$ & 10 & Insulin & Mild NPDR & Advanced PDR \\
\hline
\end{tabular}

\section{Carotid scanning data:}

IMT: Ranged from $0.06 \mathrm{~cm}$ to $0.2 \mathrm{~cm}$ ipsilateral to the eye with more advanced diabetic changes, with mean $0.1035 \mathrm{~cm}, \mathrm{SD} \pm 0.036$ which showed marginal increase than normal values. While on the ipsilateral side of eye with less advanced diabetic retinopathy the IMT ranged from $0.05 \mathrm{~cm}$ $0.19 \mathrm{~cm}$, with mean $0.09, \mathrm{SD} \pm 0.035$, and $p$-value was 0.3 .

$45 \%$ of patients had increased IMT, $35 \%$ had bilateral increased IMT \& $10 \%$ had increased IMT ipsilateral to the eye with more advanced diabetic retinopathy.

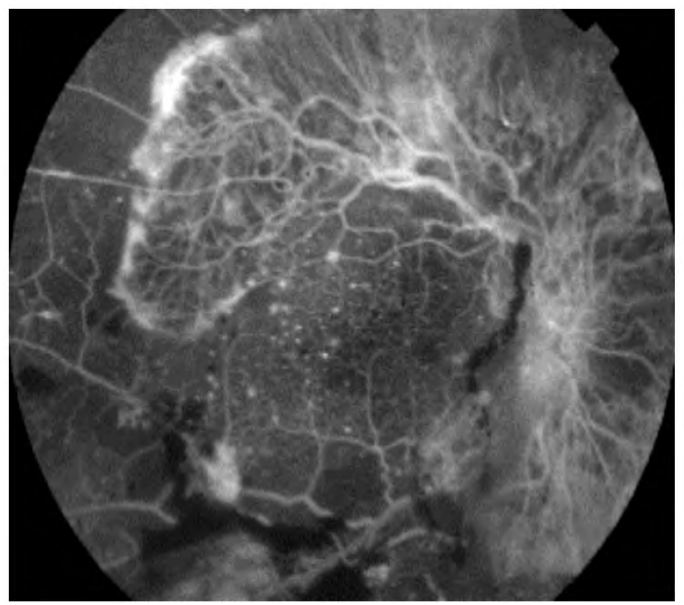

Carotid artery flow parameters:PSV of ICA ipsilateral to eye with more advanced diabetic retinopathy ranged $19-64 \mathrm{~cm} / \mathrm{s}$ with mean velocity $48 \mathrm{~cm} / \mathrm{s}, \mathrm{SD} \pm 11.84$ compared to PSV of ICA ipsilateral to eye with less advanced diabetic retinopathy that ranged $30-91 \mathrm{~cm} / \mathrm{s}$ with mean velocity $59 \mathrm{~cm} / \mathrm{s}, \mathrm{SD} \pm 20.08$, and $p$-value 0.023 .

Concerning the RI, $15 \%$ had increased RI on the ipsilateral ICA to eye with more advanced diabetic retinopathy. It ranged from 0.5 to 1 with mean $0.65 \pm 0.11$ on the ipsilateral side to eye with more advanced diabetic retinopathy, While the RI of ICA ipsilateral side to eye with less advanced diabetic retinopathy ranged $0.5-0.77$ with mean $0.60 \pm 0.08$, and $p$-value 0.12 .

Presence of plaque: $50 \%$ had CCA and/or ICA plaques, all were ipislateral to the eye with more advanced diabetic retinopathy, leading to stenosis in all of them with a degree of stenosis ranged $15 \%-50 \%$ and mean $30.5 \%$ stenosis. Three patients had $50 \%$ stenosis, one patient had $35 \%$ stenosis, one patient had $30 \%$ stenosis, 3 patients had $20 \%$ stenosis and 2 patients had $15 \%$ stenosis.

While the degree of carotid system stenosis among all patients ranged 0\%-50\% stenosis with mean $15 \%$ stenosis.

It was noticed that all the patients with different degrees of carotid stenosis developed PDR ipsilateral to the side of stenosis except for one patient (case no. 7) who had NPDR. That can raise a suspicion for correlation between the degree of carotid stenosis and the presence PDR.

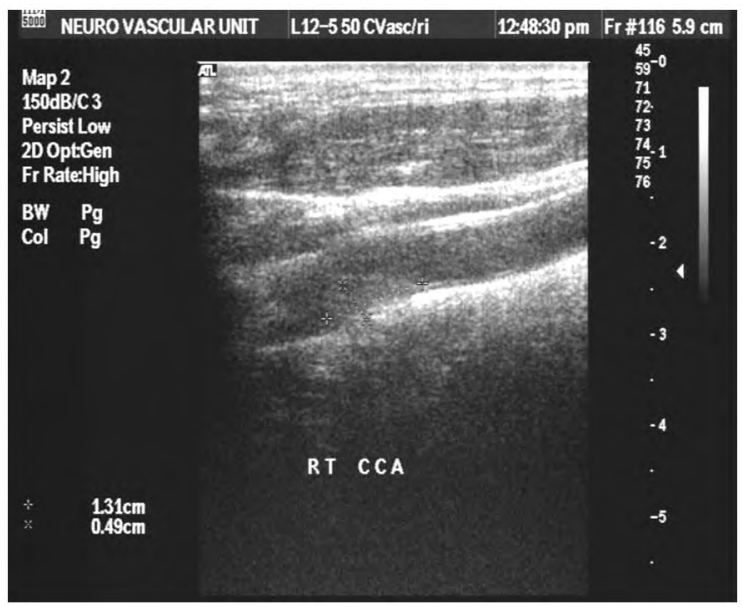

Fig. (1): Case no 8 with right advanced PDR and right CCA plaque causing 50\% stenosis.

\section{Discussion}

Klein et al., in 2000 suggested that evaluation of retinal arterial changes may allow assessment of the independent contribution of arteriolar disease to various ischemic syndromes in the heart, brain and other organs. Additionally, retinopathy has been found to be associated with prevalent coronary heart disease, stroke, and carotid artery thickening and endothelial dysfunction [6] 
In our study $50 \%$ of patients had carotid stenosis ranging $15 \%-50 \%$ with mean $30.5 \%$ all were ipsilateral to eye with more advanced diabetic retinopathy. Nine eyes had PDR and only one patient who had NPDR (case no. 7), this raises the suspicion for correlation between the degree of carotid and the presence PDR. Dogru et al., [7] in a clinical study in Japan carried on 19 patients with type 2 $\mathrm{DM}$ and asymmetric diabetic retinopathy in a trial to identify modifying factors related to the development of diabetic retinopathy asymmetry. They found five patients with ipsilateral carotid stenosis $>90 \%$ had PDR. Five eyes with delayed arm-retina circulation time on fluorescein angiography also had low retinal artery perfusion pressure on ophthalmodynamomety. These 5 eyes with PDR were confirmed to have ipsilateral carotid stenosis $>90 \%$ after carotid angiography and/or Doppler ultrasonography. The fellow eyes had NPDR. Three eyes with total carotid occlusion also had iris neovascularization.

Moderate ipsilateral carotid obstructive disease has previously been shown to be associated with protection against PDR. The protective effect of ipsilateral carotid occlusive disease has been speculated to be a result of reduction in the retinal arterial perfusion pressure [8] but this theory does not agree with our study or Dogru et al., findings, and Duker et al., [9] contradicted this hypothesis too and reported that two of their patients had PDR ipsilateral to severe carotid stenosis.

There are conflicting reports regarding the effect of carotid stenosis on diabetic retinopathy. Most recent reports indicate that carotid stenosis is associated with ipsilateral worsening of diabetic retinopathy [8]. However, relative ipsilateral sparing from diabetic retinopathy has also been described [10]. A possible explanation for these conflicting reports is may be due to difference in time of onset and relative severity of the two pathologies. For example, if moderate carotid stenosis occurs before the onset of diabetic retinopathy, an ipsilateral decrease in the severity of diabetic retinopathy may be expected on the basis of protection against the known adverse effects of hypertension on diabetic retinopathy. Conceivably, the degree of carotid stenosis may not be severe enough to cause venous stasis retinopathy. Conversely, if significant diabetic retinopathy is present prior to severe carotid occlusion, the added ischemic insult might precipitate a progression of the retinopathy ipsilateral to the carotid stenosis $[\mathbf{1 1 , 1 2}]$

In our study $45 \%$ of our patients had increase in IMT with mean $0.1035 \mathrm{~cm}$. Malecki et al. [13], in a study carried in Poland in 2008 on 182 type 2 diabetic patients identified DR as an independent predictor of increased IMT in type $2 \mathrm{DM}$. As found that IMT was larger in DR patients when compared to type $2 \mathrm{DM}$ subjects without this microvascular complication. After taking into account the multiple regression analysis of conventional atherosclerosis risk factors, such as diabetes duration and control, lipid abnormalities, smoking status or arterial hypertension, DR remained an independent risk factor for IMT increase. Several studies have evaluated the association between IMT and diabetic microangiopathic complications. In the Atherosclerosis Risk in Communities Study and in the Chennai Urban Rural Epidemiology Study the link between diabetic retinopathy and IMT was independent of age, diabetes duration and glucose control [14].

In our study $50 \%$ of patients had carotid plaques (CP) all were ipsilateral to eye with more advanced diabetic retinopathy. Vigili de Kreutzenberg et al. [15], in a study carried in Italy in 2009 on 662 patients with type $2 \mathrm{DM}$ confirmed a high prevalence of $\mathrm{CP}(\mathrm{s})(73 \%)$ in type 2 diabetic patients with a mean age of about 66 years. Due to this high prevalence, detection of CP is likely to override the information provided by IMT measurement in their cohort. However, when they repeated statistical analyses considering IMT as the independent variable, predictors of IMT were the same as of $\mathrm{CP}$. These results strengthen the association between micro- and macroangiopathy. In their study, they found that retinopathy is more prevalent in diabetic patients with $\mathrm{CP}(\mathrm{s})$ than in those without, after correction for potential confounders. In their study, they show a linear correlation between severity of microangiopathies and degree of carotid atherosclerotic stenosis. Thus, patients with more advanced stages of retinopathy had more stenotic $\mathrm{CP}(\mathrm{s})$ than patients with early retinopathy, independently of confounding factors.

We concluded that since carotid stenosis is a predominant factor in producing marked asymmetric retinopathy, we recommend early investigation for detecting any carotid system plaques, to guard against future strokes through early and appropriate treatment strategies.

The limitations of this study included small sample size, absence of long term followup as it was a cross sectional study. Recommendations for prospective researches on a larger diabetic population, with control group to confirm these results and detect any underlying confounders. 


\section{References}

1- KLEIN R., KLEIN B.E., MOSS S.E., et al.: The Wisconsin Epidemiologic Study of Diabetic Retinopathy. II, III. Prevalence and risk of diabetic retinopathy when age at diagnosis is less than 30 years. Arch. Ophthalmology, 102: 520-6, 1984.

2- AGARDH E. and AGARDH C.D.: Diabetic retinopathy. In: De fronzo R.A., Ferrannini E., Keen H., Zimmet P., editors. International text book of diabetes mellitus. 3 rd ed. Vol. 2. Chichester, England: John Wiley, p. 1187-206, 2004.

3- BALASUBRAMANYAM M., REMA M. and PREMANAND C.: Biochemical and molecular mechanisms of diabetic retinopathy. Curr. Sci., 83: 1506-14, 2002.

4- JACK KANSKI and BRAD BOWLING: Clinical ophthalmology 7th edition, 537-541, 2011.

5- ZWIEBEL W.J.: Duplex sonography of the cerebral arteries: efficacy, limitations, and indications. AJR, 158: 2936, 1992.

6- KLEIN R., SHARRETT A.R., KLEIN B.E., et al.: Are retinal arteriolar abnormalities related to atherosclerosis?. The atherosclerosis risk in communities study. Arterioscler Thromb. Vasc. Biol., 20: 1644-50, 2000.

7- M. DOGRU, MASANORI INO-UE, M. NAKAMURA, et al.: Modifying factors related to asymmetric diabetic retinopathy. Eye, 12, 929-933, Royal College of Ophthalmologists, 1998.

8- GAY A.I. and ROSENBAUM A.L.: Retinal artery pressure in asymmetric diabetic retinopathy. Arch. Ophthalmol., 75: 758-62, 1966.

9- DUKER J.S., BROWN G.C., BOSLEY T.M., et al.: Asymmetric proliferative diabetic retinopathy and carotid artery disease. Ophthalmology, 90: 869-74, 1990.

10- ROWLANDS A.G., PALIMAR P. and ENEVOLDSON T.P.: Ipsilateral proliferative diabetic retinopathy in carotid stenosis. Eye, 15: 110-111, 2001.

11- STRATTON I.M., KOHNER E.M., ALDINGTON S.J., et al.: UKPDS 50: Risk factors for incidence and progression of retinopathy in Type II diabetes over 6 years from diagnosis. Diabetologia., 44: 156-163, 2001.

12- McCRARY J.A., III: Venous stasis retinopathy of stenotic or occlusive carotid origin. J. Clin. Neuroophthalmol., 9: 195-199, 1989.

13- MALECKI M.T., OSMENDA G., WALUS-MIARKA M., et al.: Retinopathy in type 2 diabetes mellitus is associated with increased intima-media thickness and endothelial dysfunction. Eur. J. Clin. Invest, 38 (12): 925-930, 2008.

14- KLEIN R., SHARRETT A.R., KLEIN B.E., et al.: The association of atherosclerosis, vascular risk factors, and retinopathy in adults with diabetes: The atherosclerosis risk in communities study. Ophthalmology, 109: 122534, 2002.

15- VIGILI de KREUTZENBERG A.S., CORACINA A.A., VOLPI A., et al.: Microangiopathy is independently associated with presence, severity and composition of carotid atherosclerosis in type 2 diabetes. 2009 Elsevier B.V. Nutrition, Metabolism \& Cardiovascular Diseases, 21: 286-293, 2011

\section{إعتلال الشبكية السكرى غير المتماثل وقصور الشرايين السباتية ؛ دراسة مقارنة}

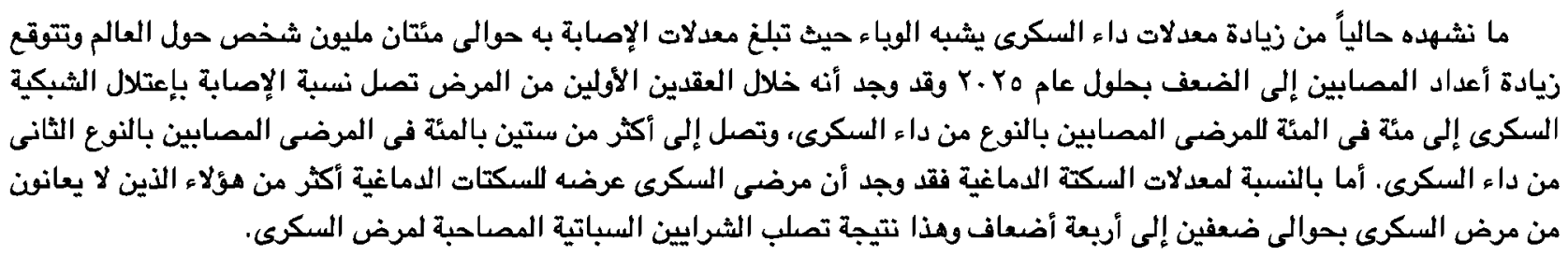

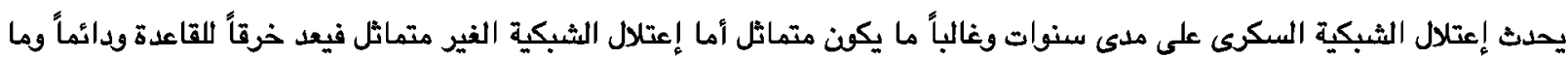
يكن وداءه سبب يجب البحث عنه، حيث يوجد العديد من الأسباب سواء بالعين أو بالجسم التى قد تؤلدى إلى علىن التماتل بين حدة الاعتلال السكرى بالعينين.

الشبكية السكرى هذه الدراسة إلى إيجاد رابط بين تصلب الشرايين السباتية وحدة إعتلال الشبكية السكرى فى المرضى الذين يعانعن من إعتلال

وقد وجدنا أن خمسون بالمئة من المرضى هذه الدراسة يعانون من ضيق بالشرايين السباتية وأن متوسط نسبة الضيق 0 ــ بـ نتيجة وجود

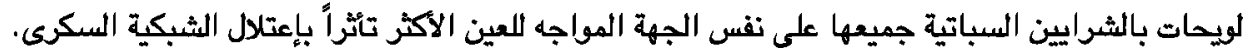

